\title{
Analysis of Characteristic Rule of Power Grid Development
}

\author{
Jun $\mathrm{Li}^{1, \mathrm{a}}$, Dong Peng ${ }^{1, \mathrm{~b}}$, Hui $\mathrm{Li}^{1, \mathrm{c}}$, Jianfeng Shi ${ }^{2, \mathrm{~d} \text {, * }}$ \\ ${ }^{1}$ State Power Economic Research Institute, China State Grid Corp, Beijing, 100000, China \\ ${ }^{2}$ Department of Economic Management, North China Electric Power University, Baoding, 071000, \\ China \\ aemail: liquan201606@163.com, bemail: email:Islzg@foxmail.com, 'email: \\ bjgw_Ih@163.com, demail: sjf201509@163.com, ${ }^{\star}$ corresponding author
}

Keywords: Power Grid, Characteristic Quantity, Rule of Development

\begin{abstract}
China is launching a campaign to replace fossil fuels with renewable energy. However, the vast majority of renewable energy needs to be converted into electricity before it can be supplied to consumers, therefore, the importance of power grid which is the transmission and distribution carrier of power will become more and more significant. Give that the developed countries have established a complete system of power grid, China can learn from their development experience of power grid to plan the development of power grid. In order to explore the experience of power grid development in developed countries, this paper fist combines the qualitative and quantitative analysis methods to summarize the development rule of power grid in developed countries based on the characteristics quantity of power grid development. Secondly, this paper makes clear the current development stage and the future development trend of China power grid according to the rule of power grid development in developed countries and the development characteristics of China power grid. Finally, some policy recommendations are provided to the future development of China power grid.
\end{abstract}

\section{Introduction}

With the increasing depletion of fossil fuels and the growing threat of global climate change, more and more attention is paid to clean energy and renewable energy by international community in recent decades [1]. As the largest energy consumer and greenhouse gas emitter, China is facing increasing international pressure on energy conservation and emissions reduction [2]. In order to cope with the contradiction of energy supply and climate change, China is promoting the development of clean energy and renewable energy to replace the use of fossil fuels gradually. In this context, the energy structure of China will have a major change [3]. It should be noted that the vast majority of renewable energy needs to be converted into electricity before it can be supplied to consumers, therefore, the importance of power grid which is the transmission and distribution carrier of power will become more and more significant. Large-scale clean energy and renewable energy access to power grid will bring higher requirement for the security, adaptability and resource optimization of power grid [4]. Give that the developed countries have established a complete system of power grid, China can learn from their development experience of power grid to plan the development of power grid.

Research on the development of power grids can be traced back to the middle of the last century. Lawton, F. L. [5] reviewed the organization, development and resources of the Russian power industry, and made a comment on design and construction of power plants, the various transmission systems and the manufacturing processes of power generation equipment. Arakawa, F. [6] described the development of the Japanese power system in stages, and noted that the current stage of power system in Japan is in the era of intelligent electricity. Nam, M. H. [7] studied the early development of electric power in South Korea, and found that the development of electric lighting was conducive to the modernization of the country. On the basis of reviewing the development process and current situation of the French power grid, Han Feng et al. [8] summarized the development characteristics and planning ideas of French power grid. Through summarizing the 
development of power grid technology, Zhou Xiaoxin et al. [9] divided the power grid into three stages and compared the main characteristics of the three generation power grid. The power grid is often regarded as a part of the power industry to be studied in existing literature, and little literature regarded power grid as single study object. In addition, the existing literature often focuses on the development of national or regional power grid rather than horizontal comparison of power grid development in different countries or region, therefore, they cannot sum up the common rule of power grid development.

Aiming at the defects in the existing research, this paper fist combines the qualitative and quantitative analysis methods to summarize the development rule of power grid in developed countries based on the characteristics quantity of power grid development. Secondly, this paper makes clear the current development stage and the future development trend of China ( $\mathrm{CHN}$ ) power grid according to the rule of power grid development in developed countries and the development characteristics of China power grid. Finally, some policy recommendations are provided to the future development of China power grid.

\section{Data Sources}

Based on the availability of indicator data and the relevance between indicator and research object, this paper selects the per capita electricity consumption, per capita installed capacity, transmission and distribution losses, the ratio of fossil fuels power generation, the ratio of renewable energy power generation (besides hydropower) as characteristics quantity to show the development of power grid. The basic data used in this paper is mainly from the World Bank (WB), the International Energy Agency (IEA), and the "China Electric Power Yearbook". Taking into account the population, economy, land area and power grid development, this paper selects the United States (USA), Britain (UK), France (FRA), Australia (AUS), Japan (JPN) and South Korea (KOR) as the research group of developed countries. In order to eliminate the difference in the total amount, transmission and distribution losses, the ratio of fossil fuel power generation, the ratio of renewable energy power generation are expressed in proportion.

\section{Characteristics Analysis}

Per capita Electricity Consumption. Electricity consumption can reflect the level of power grid construction and economic development in a country. Because the difference of total electricity consumption caused by the region's population difference can be excluded, per capita electricity consumption makes electricity consumption between countries more comparable [10].

As shown in Figure1, the per capita electricity consumption overall showed a rising trend in seven countries. There was large gap between developed countries in per capita electricity consumption. The per capita electricity consumption of United States was 12985KWh, which was higher than that of other countries. The per capita electricity consumption of Britain was 5407KWh, which was lower than that of other countries. The growth rate of per capita electricity consumption overall showed a decreasing trend, and the per capita electricity consumption presented significant saturation characteristics in developed countries (besides South Korea). This phenomenon indicates that there is an upper limit for the per capita electricity consumption in a country [11]. The per capita electricity consumption of China has been at a low level before 2000, and then it got into a rapid development period. The growth trend of per capita electricity consumption in China growth after 2000 was similar to Japan in the 1960s-1970s, that was the per capita electricity consumption would continue to maintain growth, but the growth rate would be further slowed. According to the development experience of the developed countries and the development trend of china, per capita electricity consumption of China will continue to increase in the future, but the growth rate will continue to decline, and the peak of per capita electricity consumption will be reached. 


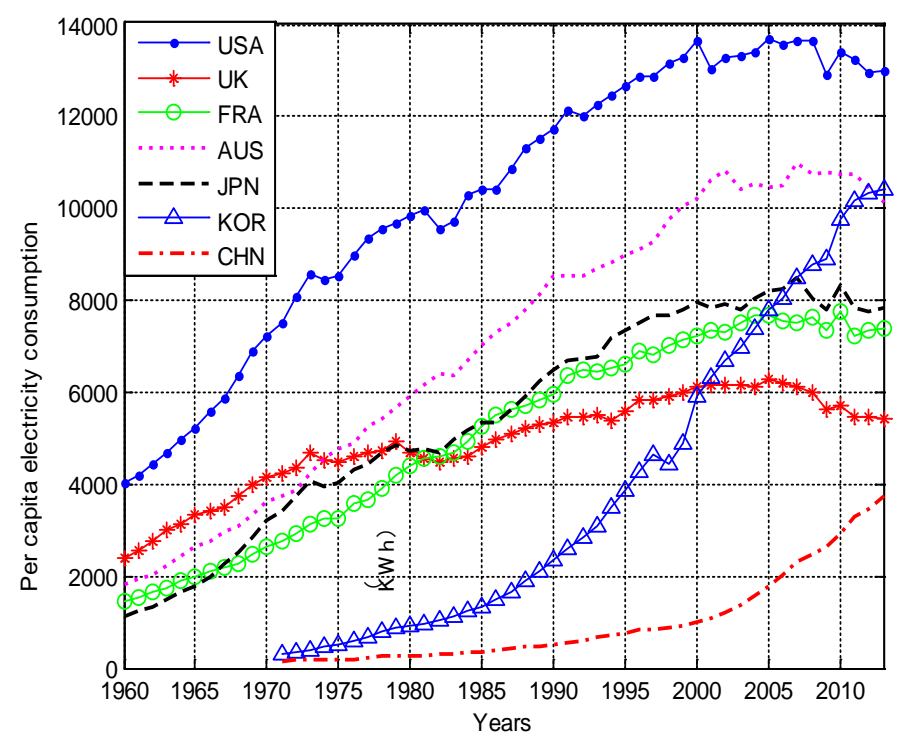

Figure.1. Per capita electricity consumption in seven countries

Per Capita Installed Capacity. The installed capacity reflects the level of power construction in an area and the estimation of power consumption by the power generation enterprises in the future [12]. Give that the difference caused by regional population is exclude, per capita installed capacity makes the installed capacity between countries have a stronger comparability. There was large gap between developed countries in per capita installed capacity. However, the gap of per capita installed capacity between developed countries is less than that of the per capita electricity consumption. The per capita installed capacity of United States was 3099KWh, which was higher than that of other countries. The per capita installed capacity of Britain was $1466 \mathrm{KWh}$, which was lower than that of other countries. The per capita installed capacity of the United States is 2.1 times larger than that of the United Kingdom. As shown in Figure2, the per capita installed capacity overall showed a rising trend in seven countries. There is a great difference in the development trend of per capita installed capacity between China and developed countries. The per capita installed capacity of developed countries (besides South Korea) grew slowly during 1980-2013, however, the per capita installed capacity of China increased by 11.8 times at the same time, which is far higher than developed countries. The per capita installed capacity of China got into a rapid development period after 2005, this trend is consistent with the growth trend of per capita electricity consumption after 2005. The current per capita installed capacity of China is similar to South Korea in 1996, which is far below the developed countries. According to the development experience of the developed countries and the development trend of china, per capita installed capacity of China will continue to increase in the future, but the growth rate will decline.

Transmission and Distribution Losses. Transmission and distribution losses are the main economic and technical indicators that comprehensively reflect the planning and operation level of power grid. The transmission and distribution losses refer to the loss rate of transmission and distribution. As shown in Figure3, the transmission and distribution losses were in a state of fluctuation during the observation period in Britain, and no consistent upward or downward trend can be observed. However, the transmission and distribution losses overall showed the trend of first decline in volatility then smooth in other developed countries. There was gap between developed countries in transmission and distribution losses. Britain has the highest losses of transmission and distribution, which reached $7.53 \%$. South Korea has the lowest losses of transmission and distribution, which was 3.4\%. Transmission and distribution losses of China basically maintain at $8 \%$ in the 1971-1982, and then began to fall. Transmission and distribution losses of China were $5.8 \%$ in 2014, which is similar to the United States. The transmission and distribution losses of China will continue to decline according to the experience of Japan and South Korea, however, the reduction space is extremely limited according to the experience of United States. Take the similarity between China and the United States on the land area into account, the decline range of 
transmission and distribution losses of China must be limited in the future.

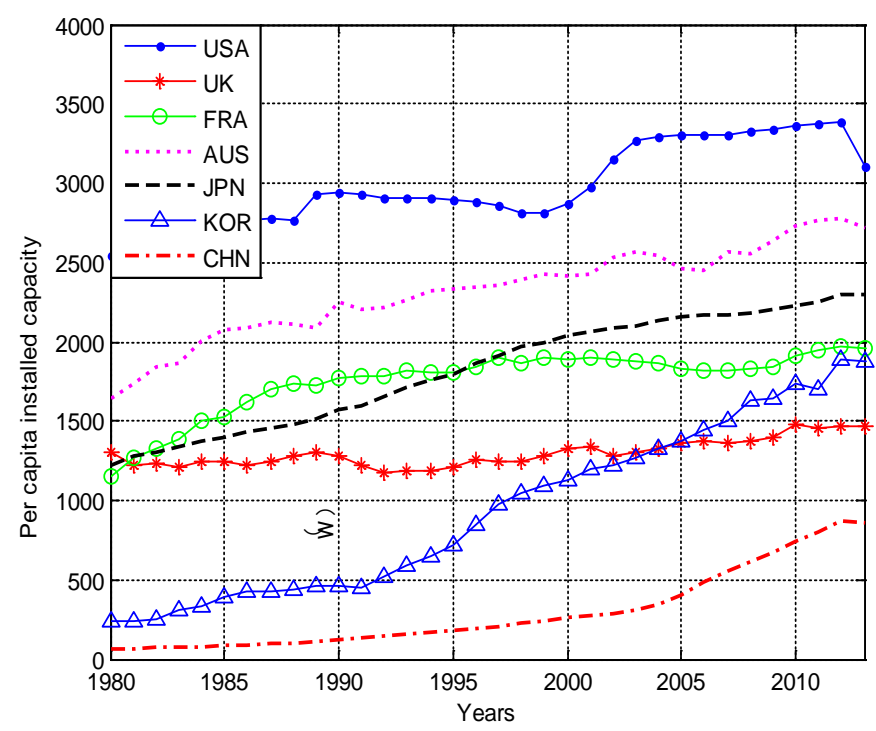

Figure.2. Per capita installed capacity in seven countries

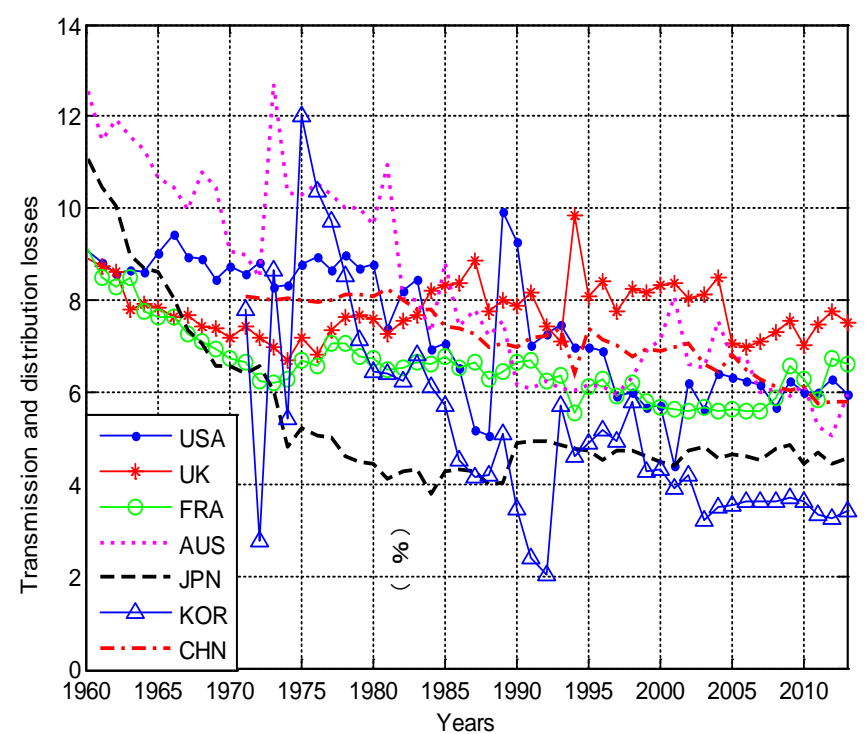

Figure.3. The transmission and distribution losses in seven countries

The Ratio of Fossil Fuel Power Generation. The ratio of fossil fuel power generation refers to the proportion of electricity generated by oil, natural gas and coal energy to total electricity generation [13]. As shown in Figure4, there was large difference between developed countries in the ratio of fossil fuel power generation, and no consistent development trend can be found. The ratio of fossil fuel power generation first increased then decreased and increased last in Japan and South Korea, and the volatility of Japan was less than that of South Korea. The ratio of fossil fuel power generation showed a downward trend in volatility in United States and Britain, and the decline range in Britain was greater than United States. The ratio of fossil fuel power generation in France was much less than other countries, and which could be attributed to its proportion of nuclear power generation was much higher than other countries. The ratio of fossil fuel power generation of China perennially floated in $80 \%$, and the decline could not be found until 2008. Due to the implement of policies to encourage new energy power generation, the ratio of fossil fuel power generation of China will continue to decline in the future. However, the decline range of the ratio of fossil fuel power generation of China must be limited in the future, only if China will built more nuclear power station in the future. 


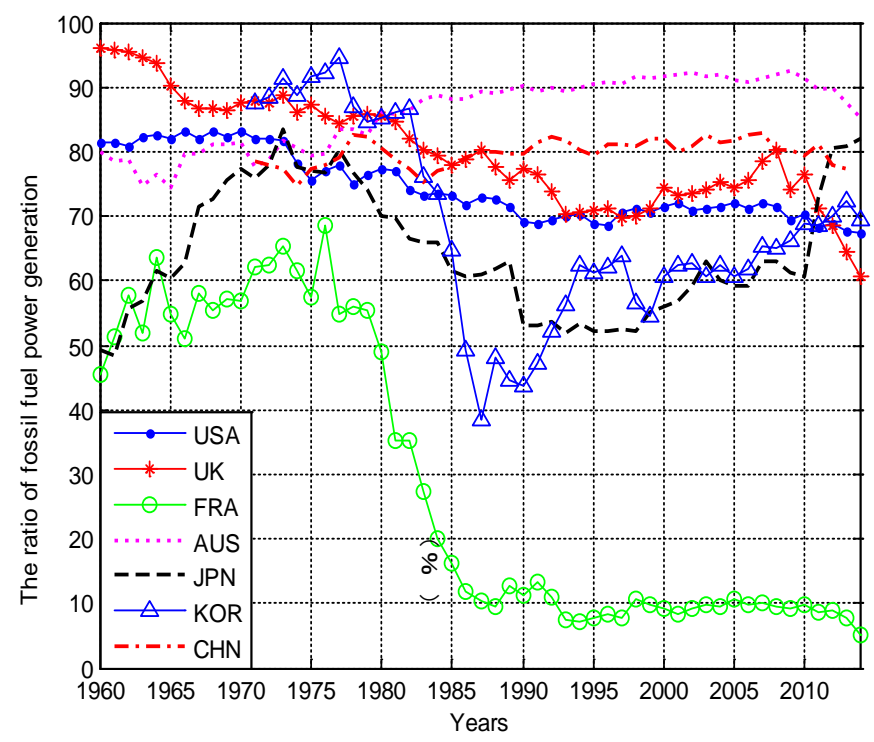

Figure.4. The ratio of fossil fuel power generation in seven countries

The Ratio of Renewable Energy Generation. The ratio of renewable energy power generation refers to the proportion of electricity generated by renewable energy (besides hydropower) to total electricity generation. As shown in Figure4, the ratio of renewable energy generation increased slowly in initial stage and increased rapidly in late stage in seven countries, however, the development process showed a significant difference. The ratio of renewable energy generation of Britain was $17.6 \%$ in 2014, which was higher than that of other countries. The growth rate of renewable energy generation is rapid in Britain, and the ratio of renewable energy generation increased from $0.19 \%$ in 1990 to $17.6 \%$ in 2014 . The ratio of renewable energy generation of South Korea was $0.8 \%$ in 2013, which was lower than that of other countries. The ratio of renewable energy generation increased slowly in China before 2005, but then the growth rate accelerated. Although the ratio of renewable energy generation in China is lower than developed countries (besides South Korea), the gap is not wide. Due to the implement of policies to encourage renewable energy generation, the ratio of renewable energy generation of China will continue to increase in the future [14].

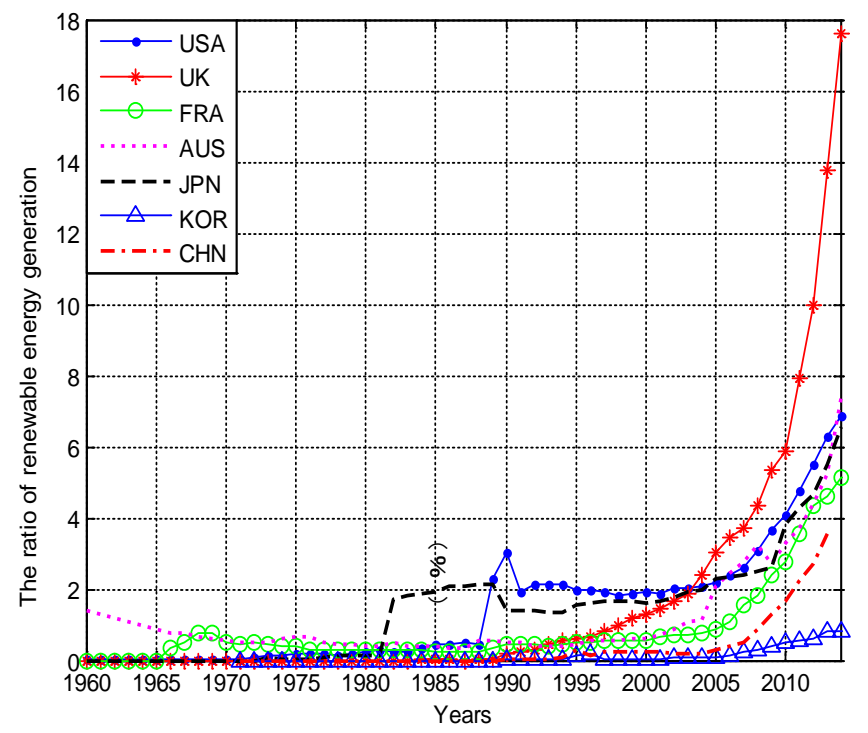

Figure.5. The ratio of renewable energy generation in seven countries

\section{Discussion}

This paper analyzed the development of power grid in developed countries, and the following 
development rules were found. Per capita electricity consumption has shown a significant saturation characteristic in developed countries. However, Per capita electricity consumption still maintains a rapid growth rate in China, but the growth rate is expected to decrease in the future; Per capita installed capacity grew slowly and the saturation characteristic is gradually revealed in developed countries. However, Per capita installed capacity still maintains a rapid growth rate in China, but the growth rate is expected to decrease in the future; In terms of transmission and distribution losses, developed countries have experienced the development process from falling to stagnation. Transmission and distribution losses of China are expected to decline in the future, however, the decline space is limited; In terms of the ratio of fossil fuel power generation, there is no consistent development trend can be found. It can be attributed to the development trend of Japan and South Korea is different from other developed countries. If the Japan and South Korea are removed, the ratio of fossil fuel power generation showed a significant downward trend in other developed countries. The ratio of fossil fuel power generation of China will continue to decline in the future. However, the decline range of the ratio of fossil fuel power generation of China must be limited in the future. In terms of the ratio of the ratio of renewable energy generation, an accelerated growth process can be found in seven countries. The ratio of renewable energy generation of China will continue to increase in the future.

In conclusion, China should continue to strengthen the power grid construction to meet the growing demand for electricity consumption. However, Electricity consumption has already passed the stage of accelerated growth and entered the stage of deceleration growth, therefore, the focus of power grid construction should also be changed in the future. The power grid should enhance absorptive capacity of renewable energy in the premise of ensuring the stability of power grid operation.

\section{Acknowledgement}

In this paper, the research was sponsored by This study was financially supported by the National Grid Science and Technology Project of China State Grid Corp (Project Name: Research on the Method and Application of Reasonable Investment of Power Grid Considering the Difference of Development Needs).

\section{References}

[1] Kishorekumar, P., Jose, J.. Intergovernmental panel on climate change: fourth assessment report summary for policymakers. International Legal Materials, 2008. 47(1), 99-121.

[2] Li, J. Y., Shi, J. F., Li, J. C.. Exploring Reduction Potential of Carbon Intensity Based on Back Propagation Neural Network and Scenario Analysis: A Case of Beijing, Energies, 2016. 9(8), 615.

[3] Groba, F., Cao, J.. Chinese renewable energy technology exports: the role of policy, innovation and markets. Environmental and Resource Economics, 2015. 60(2), 243-283.

[4] Rifkin, J.. The third industrial revolution : how lateral power is transforming energy, the economy, and the world. Survival, 2012. 2(2), 67-68.

[5] Lawton, F. L.. Power development in the USSR. Transactions of the American Institute of Electrical Engineers Part III Power Apparatus \& Systems, 1962. 81(3), 385-397.

[6] Arakawa, F.. History of power systems development in Japan. Electric Power, 2007 IEEE Conference on the History of (pp.1-9). IEEE, 2007.

[7] Nam, M. H.. Early history of South Korean electric light and power development. Electric Power, 2007 IEEE Conference on the History of (pp.192-200), 2007.

[8] Han, F., Li, H., Wang, Z. D., Liu, J. Q., Wang, Y.. Development analysis of French power grid and its enlightenment to China. Power system technology, 2009. 33 (8), 41-47. 
[9] Zhou, X. X., Chen, S. Y., Lu Z. X.. Review and Prospect of power grid and power grid technology development -- discussionon the three generation of the grid. Chinese Journal of Electrical Engineering, 2013. 36 (22), 1-11.

[10] Kula, F., Aslan, A., Ozturk, I.. Is per capita electricity consumption stationary? time series evidence from oecd countries. Renewable \& Sustainable Energy Reviews, 2012. 16(1), 501-503.

[11] Hu, L. X., Xu, Q., Zhang, R., X., Zhao, R. X., Gan, D. Q., Wu, H.. Stage theory of power grid development. Zhejiang Electric Power, 2011. 30(12), 9-11.

[12] Doherty, R., O'Malley, M.. A new approach to quantify reserve demand in systems with significant installed wind capacity. IEEE Transactions on Power Systems, 2005. 20(2), 587-595.

[13] Sims, R. E., Rogner, H. H., Gregory, K.. Carbon emission and mitigation cost comparisons between fossil fuel, nuclear and renewable energy resources for electricity generation. Energy policy, 2003. 31(13), 1315-1326.

[14] Liu, T., Xu, G., Cai, P., Tian, L., Huang, Q.. Development forecast of renewable energy power generation in China and its influence on the GHG control strategy of the country. Renewable Energy, 2011. 36(4), 1284-1292. 